\title{
FINITE ELEMENT ANALYSIS OF SORET AND DUFOUR EFFECTS ON UNSTEADY MHD FREE CONVECTION FLOW PAST AN IMPULSIVELY STARTED VERTICAL POROUS PLATE WTH VSCOUS DISSIPATION
}

\author{
M. Gnaneswara Reddy ${ }^{1}$ and N. Bhaskar Reddy ${ }^{2}$
}

${ }^{1}$ Department of Mathematics, Acharya Nagarjuna University Ongole Campus, Ongole - 523 001, INDIA

${ }^{2}$ Department of Mathematics, Sri Venkateswara University Tirupat - 517 502, INDIA

Email:mgrsvu@gmail.com

\section{Abstract:}

The Soret and Dufour effects of an unsteady free convection flow magnetohydrodynamic and viscous dissipating fluid past an impulsively started vertical plate has been analyzed. The local unsteady similarity solutions of the transformed dimensionless equations for the flow. With appropriate transformations the boundary layer equations are transformed into nonlinear ordinary differential equations. These equations are solved numerically by a finite element method. The effects of the various parameters on the velocity, temperature and concentration profiles as well as the skin-friction coefficient, Nusselt number and Sherwood number are presented graphically and in tabulated form.

Keywords: MHD, Vertical plate,Viscous dissipation, Finite element method.

\section{NOMENCLATURE}

$U_{0} \quad$ the uniform velocity

$v(t)$ the suction velocity at the plate

$c_{p} \quad$ specific heat at constant pressure

$f$ dimensionless stream function

$g \quad$ acceleration due to gravity

Gr Grashof number

$\mathrm{Du} \quad$ Dufour number

$D_{m} \quad$ the mass diffusivity

$T_{m} \quad$ the mean fluid temperature

$M \quad$ magnetic parameter

$\mathrm{Gm}$ solutal Grashof number

$B_{0} \quad$ the magnetic induction

Pr Prandtl number

$T \quad$ temperature of the boundary layer

$T_{\infty} \quad$ temperature in the fluid far away from plate

$C$ the species concentration

$C_{\infty} \quad$ Concentration in the fluid far away from plate

$\mathrm{Nu} \quad$ Nusselt number

$C_{f} \quad$ skin-friction coefficient

\section{Greek symbols}

$\alpha \quad$ the thermal diffusivity

$u \quad$ dimensionless velocity component

$\phi \quad$ dimensionless concentration

$x, y \quad$ dimensionless cartesian coordinates

$\beta \quad$ co-efficient of thermal expansion

$\theta \quad$ dimensionless temperature

$\eta \quad$ dimensionless similarity variable

$k_{T} \quad$ the thermal diffusion ratio

Ec Eckert number

$\beta^{*} \quad$ co-efficient of concentration expansion

Sc Schmidt number

$\mu, v \quad$ dynamic and kinematic viscosities

$\rho \quad$ density of the fluid

$\sigma \quad$ electrical conductivity

$c_{s} \quad$ the concentration susceptibility

$\psi$ stream function

$\mathrm{Sr} \quad$ Soret number

Sh Sherwood number 


\section{Introduction}

Coupled heat and mass transfer finds applications in a variety of engineering applications, such as the migration of moisture through the air contained in fibrous insulation and grain storage installations, filtration, chemical catalytic reactors and processes, spreading of chemical pollutants in plants and diffusion of medicine in blood veins. Free convection flow of an incompressible viscous fluid past an infinite or semi-infinite vertical plate has been studied since long because of its technological importance. Callahan and Marner (1976) solved the problem of transient free convection with mass transfer on an isothermal vertical plate using an explicit finite difference scheme. Unsteady free convective flow on taking into account the mass transfer phenomenon past an infinite vertical porous plate with constant suction was studied by Soundalgekar and Wavre (1977). Soundalgekar (1979) studied the effects of mass transfer and free convection currents on the flow past an impulsively started vertical plate. In these studies the magnetohydrodynamic phenomena is ignored. However in metallurgical transport systems, by drawing plates in an electrically conducting fluid subjected to a transverse magnetic field, the rate of cooling can be controlled and the final desired characteristics can be further refined. Magnetohydrodynamic flows has applications in meteorology, solar physics, cosmic fluid dynamics, astrophysics, geophysics and in the motion of earthes core. Shanker and Kishan (1997) presented the effect of mass transfer on the MHD flow past an impulsively started infinite vertical plate. Elabashbeshy (1997) studied heat and mass transfer along a vertical plate in the presence of magnetic field.

In all these studies Soret / Dufour effects are assumed to be negligible. Such effects are significant when density differences exists in the flow regime. For example when species are introduced at a surafce in fluid domain, with different (lower) density than the surrounding fluid, both Soret and Dufour effects can be significant. Also, when heat and mass transfer occur simultaneously in a moving fluid, the relations between the fluxes and the driving potentials are of more intricate nature. It has been found that an energy flux can be generated not only by temperature gradients but by composition gradients as well. The energy flux caused by a composition gradient is called the Dufour or diffusion-thermo effect. On the other hand, mass fluxes can also be created by temperature gradients and this is the Soret or thermal-diffusion effect. The thermal-diffusion (Soret) effect, for instance, has been utilized for isotope separation, and in mixture between gases with very light molecular weight $\left(\mathrm{H}_{2}, \mathrm{He}\right)$ and of medium molecular weight $\left(\mathrm{N}_{2}\right.$, air), the diffusion-thermo (Dufour) effect was found to be of a considerable magnitude such that it cannot be ignored (Eckert and Drake (1972)). In view of the importance of these above mentioned effects, Dursunkaya and Worek (1992) studied diffusion-thermo and thermal-diffusion effects in transient and steady natural convection from a vertical surface, whereas Kafoussias and Williams (1995) studied the same effects on mixed free-forced convective and mass transfer boundary layer flow with temperature dependent viscosity. Recently, Anghel et al. (2000) investigated the Dufour and Soret effects on free convection boundary layer over a vertical surface embedded in a porous medium. Very recently, Postelnicu (2004) studied numerically the influence of a magnetic field on heat and mass transfer by natural convection from vertical surfaces in porous media considering Soret and Dufour effects.

Unsteady free convection flows of dissipative fluids past an infinite plate have received a little attention because of non-linearity of the governing equations. Gebhart (1962) stated that "a significant viscous dissipation may occur in natural convection in various devices which are subject to large deceleration or which operate at high rotational speeds. Viscous dissipation effects may also be present in stronger gravitational fields and in processes wherein the scale of the process is very large, e.g., on larger planets, in large masses of gas in space, and in geological processes in fluids internal to viscous bodies". Gebhart and Mollendorf (1969) considered the effects of viscous dissipation for an external natural convection flow over a surface. Soundalgekar (1972) analyzed the effect of viscous dissipative heat on the two-dimensional unsteady, free convective flow past an infinite vertical porous plate when the temperature oscillates in time and there is constant suction at the plate.

However, the study of Soret and Dufour effects on unsteady MHD free convection flow of a dissipative fluid has received a little attention. Hence, the objective of the present paper is to analyze the Soret and Dufour effects on unsteady MHD free convection flow of a viscous incompressible fluid past an impulsively started vertical porous plate by taking viscous dissipation into account. The governing equations are transformed by using similarity transformation and the resultant dimensionless equations are solved by using the finite element method. The effects of various governing parameters on the velocity, temperature, concentration, skin-friction coefficient, Nusselt number and Sherwood number are shown in figures and tables and analyzed in detail. 


\section{Mathematical Analysis}

M. Gnaneswara Reddy, N.Bhaskar Reddy / Journal of Naval Architecture and Marine Engineering 8(2011) 1-12

An unsteady two-dimensional free convection flow of a viscous incompressible electrically conducting and dissipating fluid along an impulsively started vertical porous plate is considered. The $x$ - axis is taken along the plate in the upward direction and the $y$-axis is taken normal to the plate. Initially, the plate and the fluid are at the same temperature $T_{\infty}$ and the concentration $C_{\infty}$. At time $t>0$, the plate starts moving impulsively in its own plane with a velocity $U_{0}$ and the plate temperature and concentration are raised to $T w$ and $C_{w}$ respectively and are maintained constantly thereafter. A uniform magnetic field is applied in the direction perpendicular to the plate. The fluid is assumed to be slightly conducting, and hence the magnetic Reynolds number is much less than unity and the induced magnetic field is negligible in comparison with the applied magnetic field. It is further assumed that there is no applied voltage, so that electric field is absent. It is assumed that all the fluid properties are constant except that of the influence of the density variation with temperature and concentration in the body force term (Boussinesq's approximation). Then, under the above assumptions, the governing boundary layer equations of the flow field are

Mass conservation

$$
\frac{\partial v}{\partial y}=0
$$

Momentum conservation

$$
\frac{\partial u}{\partial t}+v \frac{\partial u}{\partial y}=v \frac{\partial^{2} u}{\partial y^{2}}+g \beta\left(T-T_{\infty}\right)+g \beta^{*}\left(C-C_{\infty}\right)-\frac{\sigma B_{0}^{2}}{\rho} u
$$

Thermal energy conservation

$$
\frac{\partial T}{\partial t}+v \frac{\partial T}{\partial y}=\alpha \frac{\partial^{2} T}{\partial y^{2}}+\frac{D_{m} k_{T}}{c_{s} c_{p}} \frac{\partial^{2} C}{\partial y^{2}}+\frac{v}{c_{p}}\left(\frac{\partial u}{\partial y}\right)^{2}
$$

Species conservation

$$
\frac{\partial C}{\partial t}+v \frac{\partial C}{\partial y}=D_{m} \frac{\partial^{2} C}{\partial y^{2}}+\frac{D_{m} k_{T}}{T_{m}} \frac{\partial^{2} T}{\partial y^{2}}
$$

The initial and boundary conditions are

$$
\begin{aligned}
t \leq 0: u & =0, \quad v=0, \quad T=T_{\infty}, \quad C=C_{\infty} \\
t>0: u & =U_{0}, \quad v=v(t), \quad T=T_{w}, \quad C=C_{w} \quad \text { at } \quad y=0 \\
u & \rightarrow 0, \quad v \rightarrow 0, \quad T \rightarrow T_{\infty}, \quad C \rightarrow C_{\infty} \quad \text { as } \quad y \rightarrow \infty
\end{aligned}
$$

In order to obtain a local similarity solution in the time dependent problem under consideration, a time dependent length scale $\delta$ is taken as

$\delta=\delta(t)$

In terms of this length scale, a convenient solution of Equation (1) is considered to be in the following form

$$
v=v(t)=-v_{0} \frac{v}{\delta}
$$

where $v_{0}$ is the suction parameter.

In order to write the governing Equations and the boundary conditions in dimensionless form, the following non-dimensional quantities are introduced.

$$
\begin{aligned}
& \eta=\frac{y}{\delta}, \quad u=U_{0} f(\eta), \quad \theta(\eta)=\frac{T-T_{\infty}}{T_{w}-T_{\infty}}, \quad \phi(\eta)=\frac{C-C_{\infty}}{C_{w}-C_{\infty}}, \quad G r=\frac{g \beta\left(T_{w}-T_{\infty}\right) \delta^{2}}{v U_{0}}, \\
& G m=\frac{g \beta^{*}\left(C_{w}-C_{\infty}\right) \delta^{2}}{v U_{0}}, \quad M=\frac{\sigma B_{0}^{2} \delta^{2}}{v \rho}, \quad \operatorname{Pr}=\frac{v}{\alpha}, \quad E c=\frac{U_{0}^{2}}{c_{p}\left(T_{w}-T_{\infty}\right)}, \\
& S c=\frac{v}{D_{m}}, \quad D u=\frac{D_{m} k_{T}\left(C_{w}-C_{\infty}\right)}{c_{s} c_{p}\left(T_{w}-T_{\infty}\right)}, \quad S r=\frac{D_{m} k_{T}\left(T_{w}-T_{\infty}\right)}{v T_{m}\left(C_{w}-C_{\infty}\right)}
\end{aligned}
$$


M. Gnaneswara Reddy, N.Bhaskar Reddy / Journal of Naval Architecture and Marine Engineering 8(2011) 1-12

where $f$ is the dimensionless velocity and $\eta$ is the dimensionless variable.

In view of the Equations (6) - (8), the Equations (2), (3) and (4) reduce to the following dimensionless form

$$
\begin{aligned}
& f^{\prime \prime}+\eta\left(\frac{\delta}{v} \frac{d \delta}{d t}\right) f^{\prime}+v_{0} f^{\prime}+G r \theta+G m \phi-M f=0 \\
& -\eta\left(\frac{\delta}{v} \frac{d \delta}{d t}\right) \theta^{\prime}-v_{0} \theta^{\prime}=\frac{1}{\operatorname{Pr}} \theta^{\prime \prime}+D u \phi^{\prime \prime}+E c f^{\prime 2} \\
& -\eta\left(\frac{\delta}{v} \frac{d \delta}{d t}\right) \phi^{\prime}-v_{0} \phi=\frac{1}{S c} \phi^{\prime \prime}+S r \theta^{\prime \prime}
\end{aligned}
$$

The corresponding dimensionless boundary conditions are

$$
\begin{array}{lll}
f=1, \quad \theta=1, \quad \phi=1 & \text { at } \eta=0 \\
f \rightarrow 0, \theta \rightarrow 0, \phi \rightarrow 0 & \text { as } \quad \eta \rightarrow \infty
\end{array}
$$

Now, the Equations (9) - (11) are locally similar except $\left(\frac{\delta}{v} \frac{d \delta}{d t}\right)$, where $t$ appears explicitly. Thus, the local similarity condition requires the form $\left(\frac{\delta}{v} \frac{d \delta}{d t}\right)$ in the Equations (9) - (11) must be a constant quantity.

Hence, following Hasimoto (1956), Sattar and Hossain (1992) and Sattar et al. (2000), one can try a class of solutions of the equations (9) - (11) by assuming that

$$
\left(\frac{\delta}{v} \frac{d \delta}{d t}\right)=\lambda(\text { a constant })
$$

Integrating equation (13), we have

$$
\delta=\sqrt{2 \lambda v t}
$$

where the constant of integration is determined through the condition that $\delta=0$ when $\mathrm{T}$

$t=0$. Here the problem is considered for small time. In this case the normal velocity in Equation (7) will be large i.e., suction will be large, which can be applied to increase the lift of airfoils. From Equation (14), choosing $\lambda$ $=2$, the length scale $\delta(t)=2 \sqrt{v t}$ exactly corresponds to the usual scaling factor for various unsteady boundary layer flows (Schlichting (1968)). Since $\delta$ is a scaling factor as well as a similarity parameter, any value of $\lambda$ in Equation (13) would not change the nature of the solutions, except that the scale would be different.

In view of the Equation (13) (with $\lambda=2$ ), the Equations (9) - (11) reduce to the following dimensionless ordinary differential equations, which are locally similar in time but not explicitly time dependent.

$$
\begin{aligned}
& f^{\prime \prime}+\left(2 \eta+v_{0}\right) f^{\prime}+G r \theta+G m \phi-M f=0 \\
& \theta^{\prime \prime}+\operatorname{Pr}\left(2 \eta+v_{0}\right) \theta^{\prime}+\operatorname{Pr} D u \phi^{\prime \prime}+\operatorname{Pr} E c f^{\prime 2}=0 \\
& \phi^{\prime \prime}+\operatorname{Sc}\left(2 \eta+v_{0}\right) \phi^{\prime}+\operatorname{Sc} \operatorname{Sr} \theta^{\prime \prime}=0
\end{aligned}
$$

The corresponding boundary conditions are same as (12).

For the type of flow under consideration, the physical quantities such as the wall shear stress, surface heat flux and the surface mass flux are very important, which are given by

$$
\begin{aligned}
& \tau_{w}=\mu\left(\frac{\partial u}{\partial y}\right)_{y=0} \\
& q_{w}=-k\left(\frac{\partial T}{\partial y}\right)_{y=0} \\
& M_{w}=-D_{m}\left(\frac{\partial C}{\partial y}\right)_{y=0}
\end{aligned}
$$

The wall shear stress, surface heat flux and the surface mass flux for an impulsively started plate are

$$
\frac{\tau_{w} \delta}{\mu U_{0}}=f^{\prime}(0)
$$




$$
\begin{aligned}
& \frac{q_{w} \delta}{k\left(T_{w}-T_{\infty}\right)}=-\theta^{\prime}(0) \\
& \frac{M_{w} \delta}{D_{m}\left(C_{w}-C_{\infty}\right)}=-\phi^{\prime}(0)
\end{aligned}
$$

Hence, the dimensionless the skin-friction coefficient, Nusselt number and Sherwood number for impulsively started plate are given by

$$
\begin{aligned}
& C_{f}=\frac{2 \tau_{w}}{\rho U_{0}^{2}}=2\left(\mathrm{Re}_{\delta}\right)^{-1} f^{\prime}(0) \\
& N u=\frac{q_{w} \delta}{k\left(T_{w}-T_{\infty}\right)}=-\theta^{\prime}(0) \\
& S h=\frac{M_{w} \delta}{D_{m}\left(C_{w}-C_{\infty}\right)}=-\phi^{\prime}(0)
\end{aligned}
$$

where $\mathrm{Re}_{\delta}=\frac{U_{0} \delta}{v}$ is the Reynolds number.

\section{Solution of the problem}

The set of differential Equations (15) - (17) are highly nonlinear and therefore it cannot be solved analytically. Hence, following Reddy (1985) and Bathe (1996), the finite element method is used to obtain an accurate and efficient solution to the boundary value problem under consideration.

The convergence has been efficiently achieved by fixing infinity as 6 . The whole domain is discretized into a set of 100 line elements of equal width, each element being three-noded.

\subsection{Variational formulation}

The variational form associated with Equations (18) - (20) over a typical three-noded linear element $\left(\eta_{e}, \eta_{e+2}\right)$ is given by

$$
\begin{aligned}
& \int_{\eta_{e}}^{\eta_{e+2}} w_{1}\left\{f^{\prime \prime}+\left(2 \eta+v_{0}\right) f^{\prime}+G r \theta+G m \phi-M f\right\} d \eta=0 \\
& \int_{\eta_{e}}^{\eta_{e+2}} w_{2}\left\{\theta^{\prime \prime}+R \operatorname{Pr}\left(2 \eta+v_{0}\right) \theta^{\prime}+R \operatorname{Pr} E c f^{\prime 2}\right\} d \eta=0 \\
& \int_{\eta_{e}}^{\eta_{e+2}} w_{3}\left\{\phi^{\prime \prime}+S c\left(2 \eta+v_{0}\right) \phi^{\prime}\right\} d \eta=0
\end{aligned}
$$

Where $w 1, w 2$ and $w 3$ are the arbitrary test functions which may be viewed as the variations in the functions $f$, $\theta$ and $\varphi$ respectively.

\subsection{Finite element formulation}

The finite element method seeks an approximate solution to the differential equation over each element. The polynomial approximation of the solution within a three-noded element is of the form

$$
\begin{aligned}
& f=\sum_{i=1}^{3} f_{i}^{e} \psi_{i}^{e} \\
& \theta=\sum_{i=1}^{3} \theta_{i}^{e} \psi_{i}^{e} \\
& \phi=\sum_{i=1}^{3} \phi_{i}^{e} \psi_{i}^{e}
\end{aligned}
$$

where $f_{i}^{e}, \theta_{i}^{e}$ and $\phi_{i}^{e}$ are the values of the solution at the $i^{\text {th }}$ node of the element and $\psi_{i}^{e}$ are the shape functions for a typical element $\left(\eta_{e}, \eta_{e+2}\right)$ and are taken as 
M. Gnaneswara Reddy, N.Bhaskar Reddy / Journal of Naval Architecture and Marine Engineering 8(2011) 1-12

$\psi_{1}^{e}=\frac{\left(\eta-\frac{(2 e-1) s}{200}\right)\left(\eta-\frac{(2 e) s}{200}\right)}{\left(\frac{(2 e-2) s}{200}-\frac{(2 e-1) s}{200}\right)\left(\frac{(2 e-2) s}{200}-\frac{(2 e) s}{200}\right)}$

$(e=1,2,3, \ldots, 100)$,

$\psi_{2}^{e}=\frac{\left(\eta-\frac{(2 e-2) s}{200}\right)\left(\eta-\frac{(2 e) s}{200}\right)}{\left(\frac{(2 e-1) s}{200}-\frac{(2 e-2) s}{200}\right)\left(\frac{(2 e-1) s}{200}-\frac{(2 e) s}{200}\right)} \quad(e=1,2,3, \ldots, 100),(31)$

$\psi_{3}^{e}=\frac{\left(\eta-\frac{(2 e-2) s}{200}\right)\left(\eta-\frac{(2 e-1) s}{200}\right)}{\left(\frac{(2 e) s}{200}-\frac{(2 e-2) s}{200}\right)\left(\frac{(2 e) s}{200}-\frac{(2 e-1) s}{200}\right)} \quad(e=1,2,3, \ldots, 100)$.

where $S=6$.

The coefficients $f_{i}^{e}, \theta_{i}^{e}$ and $\phi_{i}^{e}$ are determined such that Equations (27) - (29) are satisfied in the weighted integral sense.

Taking $w_{1}=w_{2}=w_{3}=\psi_{i}^{e} \quad(i=1,2,3)$, the finite element model of the equations thus formed.

The stiffness matrix for the Equation (27) is as follows.

$\left[K_{e j}^{f}\right]\{f\}=\left[B_{e j}^{f}\right]$

where

$$
\begin{gathered}
K_{e j}^{f}=-\int_{\eta_{e}}^{\eta_{e+2}}\left(\sum_{i=1}^{3} f_{i}^{e} \frac{\partial \psi_{i}^{e}}{\partial \eta} \frac{\partial \psi_{j}^{e}}{\partial \eta}\right) d \eta+\int_{\eta_{e}}^{\eta_{e+2}}\left(\left(2 \eta+v_{0}\right)\left(\sum_{i=1}^{3} f_{i}^{e} \frac{\partial \psi_{i}^{e}}{\partial \eta}\right)\right) \psi_{j}^{e} d \eta \\
-M \int_{\eta_{e}}^{\eta_{e+2}}\left(\sum_{i=1}^{3} f_{i}^{e} \psi_{i}^{e}\right) \psi_{j}^{e} d \eta, \\
{\left[B_{e j}^{f}\right]=-G r \int_{\eta_{e}}^{\eta_{e+2}}\left(\sum_{i=1}^{3} \theta_{i}^{e} \psi_{i}^{e}\right) \psi_{j}^{e} d \eta-G m \int_{\eta_{e}}^{\eta_{e+2}}\left(\sum_{i=1}^{3} \phi_{i}^{e} \psi_{i}^{e}\right) \psi_{j}^{e} d \eta,} \\
(e=1,2,3 \ldots, 100),(j=1,2,3)
\end{gathered}
$$

and

$$
\{f\}=\left[f_{1}, f_{2}, f_{3}, \ldots, f_{201}\right]^{T} .
$$

The stiffness matrix for Equation (28) is as follows.

$\left[K_{e j}^{\theta}\right]\{\theta\}=\left[B_{e j}^{\theta}\right]$

where

$$
\begin{aligned}
& {\left[K_{e j}^{\theta}\right]=-\int_{\eta_{e}}^{\eta_{e+2}}\left(\sum_{i=1}^{3} \theta_{i}^{e} \frac{\partial \psi_{i}^{e}}{\partial \eta} \frac{\partial \psi_{j}^{e}}{\partial \eta}\right) d \eta+R \operatorname{Pr} \int_{\eta_{e}}^{\eta_{e+2}}\left(\left(2 \eta+v_{0}\right) \sum_{i=1}^{3} \theta_{i}^{e} \frac{\partial \psi_{i}^{e}}{\partial \eta}\right) \psi_{j}^{e} d \eta,} \\
& {\left[B_{e j}^{\theta}\right]=R \operatorname{Pr} E c \int_{\eta_{e}}^{\eta_{e+2}}\left(\sum_{i=1}^{3} f_{i}^{e} \frac{\partial \psi_{i}^{e}}{\partial \eta}\right)^{2} \psi_{j}^{e} d \eta,(e=1,2,3 \ldots, 100),(j=1,2,3)}
\end{aligned}
$$

and

$$
\{\theta\}=\left[\theta_{1}, \theta_{2}, \theta_{3}, \ldots, \theta_{201}\right]^{T} \text {. }
$$

The stiffness matrix for the Equation (29) is as follows.

$\left[K_{e j}^{\phi}\right]\{\phi\}=\left[B_{e j}^{\phi}\right]$

where

$$
\begin{aligned}
& {\left[K_{e j}^{\phi}\right]=-\int_{\eta_{e}}^{\eta_{e+2}}\left(\sum_{i=1}^{3} \phi_{i}^{e} \frac{\partial \psi_{i}^{e}}{\partial \eta} \frac{\partial \psi_{j}^{e}}{\partial \eta}\right) d \eta+S c \int_{\eta_{e}}^{\eta_{e+2}}\left(\left(2 \eta+v_{0}\right) \sum_{i=1}^{3} \phi_{i}^{e} \frac{\partial \psi_{i}^{e}}{\partial \eta}\right) \psi_{j}^{e} d \eta,} \\
& {\left[B_{e j}^{\phi}\right]=0,(e=1,2,3 \ldots, 100),(j=1,2,3)}
\end{aligned}
$$


and

$$
\{\phi\}=\left[\phi_{1}, \phi_{2}, \phi_{3}, \ldots, \phi_{201}\right]^{T}
$$

These system of $201 \times 201$ matrix equations are solved by the iteration scheme. Applying the given boundary conditions only a system of 195 equations remains to be solved. At the beginning of the first iteration the velocity is taken to be zero and the system of equations is solved using a Gaussian elimination method for the nodal temperature and concentration. Thus the values at the first iteration are obtained. Now, the nodal temperature and concentration values are used to get nodal velocity and then second iteration nodal temperature and concentration values are obtained. This process is repeated until the desired accuracy of 0.0005 is obtained.

\section{Results and discussion}

A representative set of numerical results is shown graphically in Figs.1-9, to illustrate the influence of physical parameters viz., the thermal Grashof number $G r$, solutal Grashof number $G m$, magnetic field parameter $M$, Prandtl number $P r$, Eckert number $E c$, Dufour number $D u$, Schmidt number $S c$, Soret number $S r$ and the suction parameter $v_{0}$ on the velocity, temperature, concentration.

The effect of the thermal Grashof number $G r$ on the velocity is presented in Fig.1. The thermal Grashof number Gr signifies the relative effect of the thermal buoyancy force to the viscous hydrodynamic force in the boundary layer. It is observed that an increase in $G r$ causes a significant increase in the velocity. Therefore, with an increase in buoyancy force due to temperature differences, the flow is accelerated in the boundary layer. Here the positive values of $\mathrm{Gr}$ correspond to cooling of the plate by natural convection.

The influence of the solutal Grashof number $G m$ on the velocity is presented in Fig.2. The solutal Grashof number $G m$ defines the ratio of the species buoyancy force to the viscous hydrodynamic force. It is found that the velocity increases considerably with a rise in $\mathrm{Gm}$. The soluatal Grashof number boosts velocity of the fluid indicating that species buoyancy has an accelerating effect on the flow field.

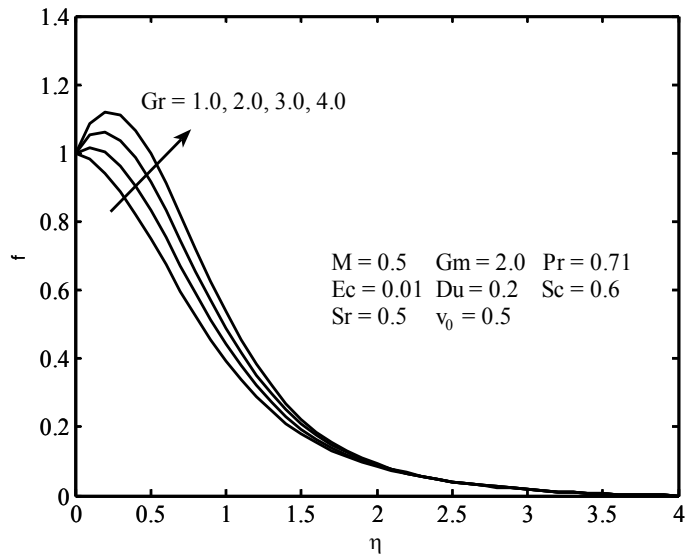

Fig.1: Velocity profiles for different values of $G r$

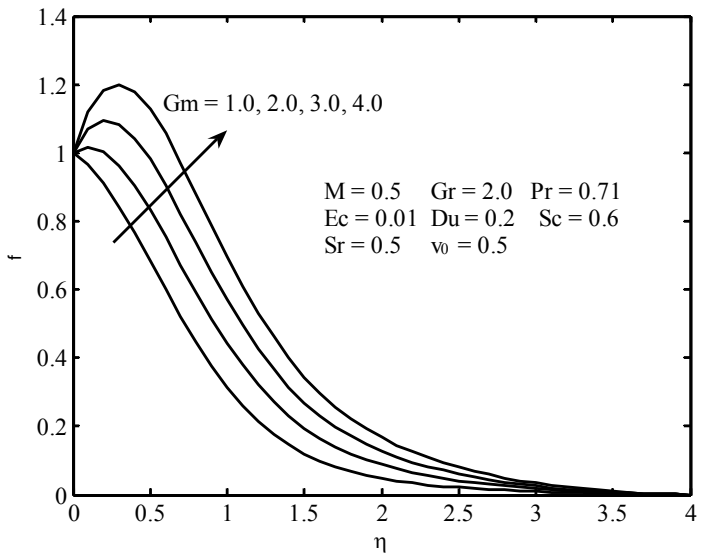

Fig.2: Velocity profiles for different values of $G m$

Fig.3 depicts the velocity profiles for different values of the magnetic field parameter $M$. It is noticed that an increase in the magnetic parameter $M$ leads to a decrease in the velocity. The application of a transverse magnetic field to an electrically conducting fluid gives rise to a resistive force called Lorentz force. This force has the tendency to slow down the motion of the fluid. Also, the boundary layer thickness decreases with an increase in the magnetic parameter.

For different values of the Prandtl number $P r$, the velocity and temperature profiles are plotted in Figs. 4(a) and 4(b). The Prandtl number defines the ratio of momentum diffusivity to thermal diffusivity. From Fig. 4 (a), it is clear that an increase in the Prandtl number leads to a fall in the velocity. From Fig.4 (b), it is observed that an increase in the Prandtl number results a decrease of the thermal boundary layer thickness and in general lower average temperature within the boundary layer. The reason is that smaller values of $\operatorname{Pr}$ are equivalent to increasing the thermal conductivities, and therefore heat is able to diffuse away from the heated surface more 
M. Gnaneswara Reddy, N.Bhaskar Reddy / Journal of Naval Architecture and Marine Engineering 8(2011) 1-12

rapidly than for higher values of $P r$. Hence in the case of smaller Prandtl numbers as the boundary layer is thicker and the rate of heat transfer is reduced.

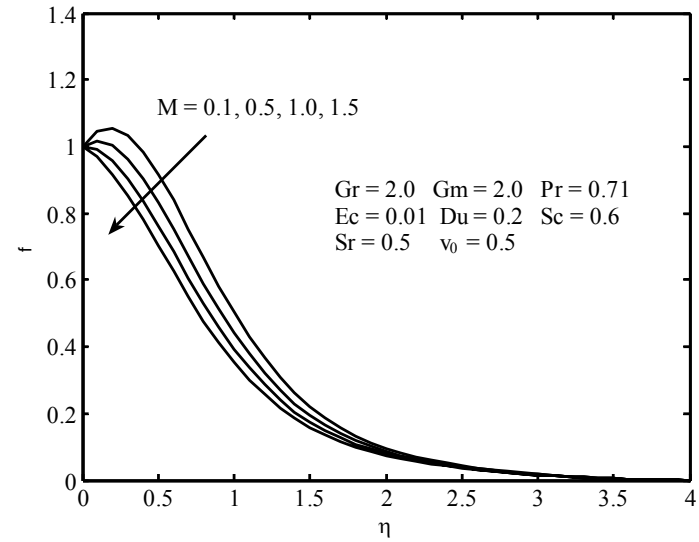

Fig.3: Velocity profiles for different values of $M$

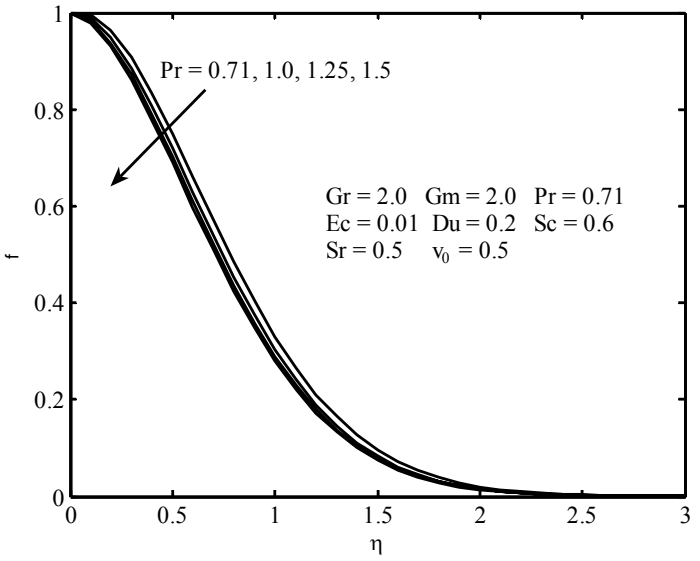

Fig.4(a): Velocity profiles for different values of $\mathrm{Pr}$

The influences of Eckert number on the dimensionless velocity and temperature functions are shown in Figs 5(a) and 5(b) respectively. The Eckert number designates the ratio of the kinetic energy of the flow to the boundary layer enthalpy difference. It embodies the conversion of kinetic energy into internal energy by work done against the viscous fluid stresses. The positive Eckert number implies cooling of the plate i.e., loss of heat from the plate to the fluid. Hence, greater viscous dissipative heat causes a rise in the temperature as well as the velocity, which is evident from Figs. 5 (a) and 5 (b).

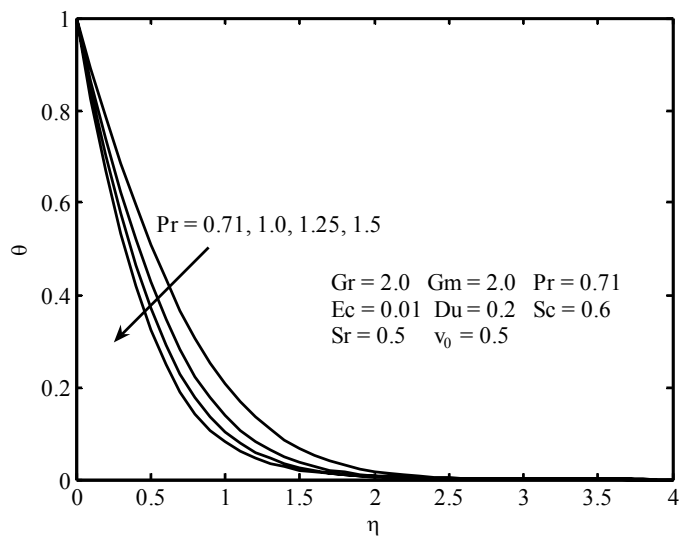

Fig.4(b): Temperature profiles for different values of $\mathrm{Pr}$

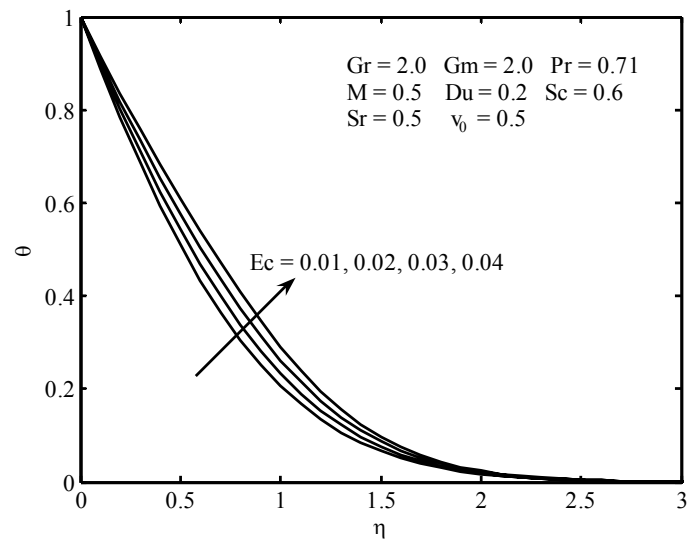

Fig.5(b): Temperature profiles for different values of $E c$

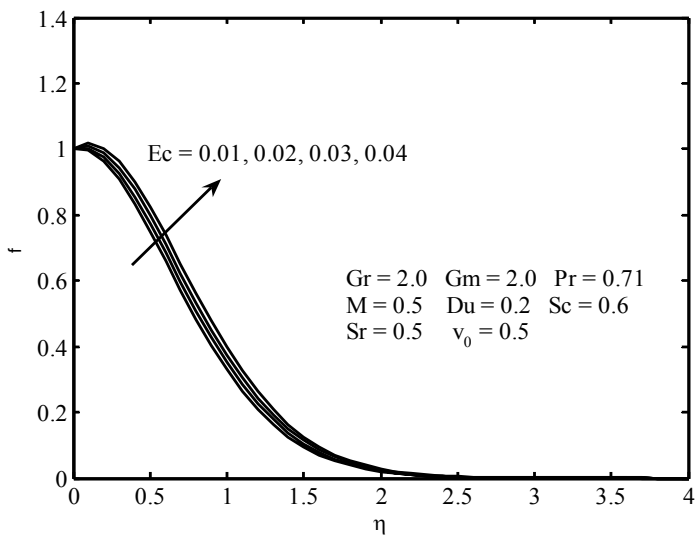

Fig.5(a): Velocity profiles for different values of $E c$

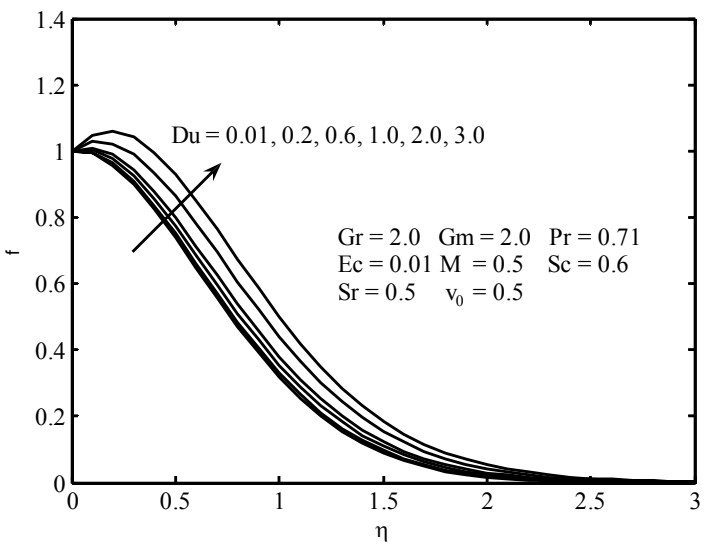

Fig.6(a): Velocity profiles for different values of $D u$ 
M. Gnaneswara Reddy, N.Bhaskar Reddy / Journal of Naval Architecture and Marine Engineering 8(2011) 1-12

For different values of the Dufour number $D u$, the velocity and temperature profiles are plotted in Figs. 6(a) and 6(b) respectively. The Dufour number $D u$ signifies the contribution of the concentration gradients to the thermal energy flux in the flow. It is observed that an increase in the Dufour number causes a rise in the velocity and temperature throughout the boundary layer. For $D u \leq 1$, the temperature profiles decay smoothly from the surface to the free stream value. However for $D u>1$, a distinct velocity overshoot exists near the plate, and thereafter the profile falls to zero at the edge of the boundary layer.

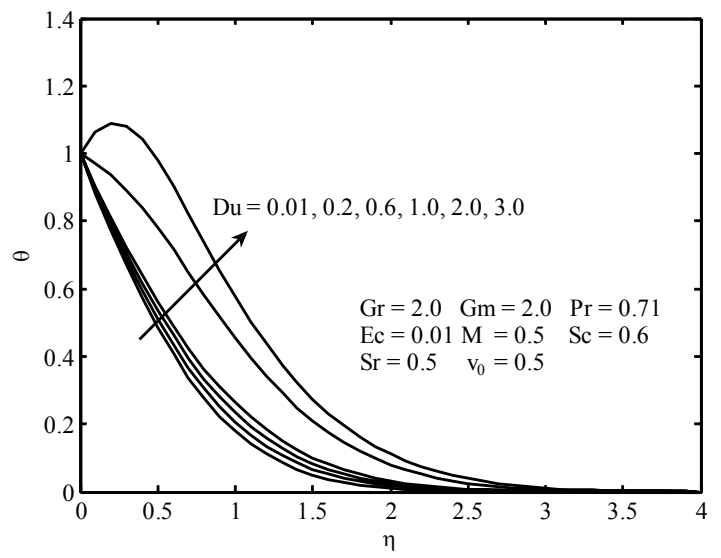

Fig.6(b): Temperature profiles for different values of $D u$

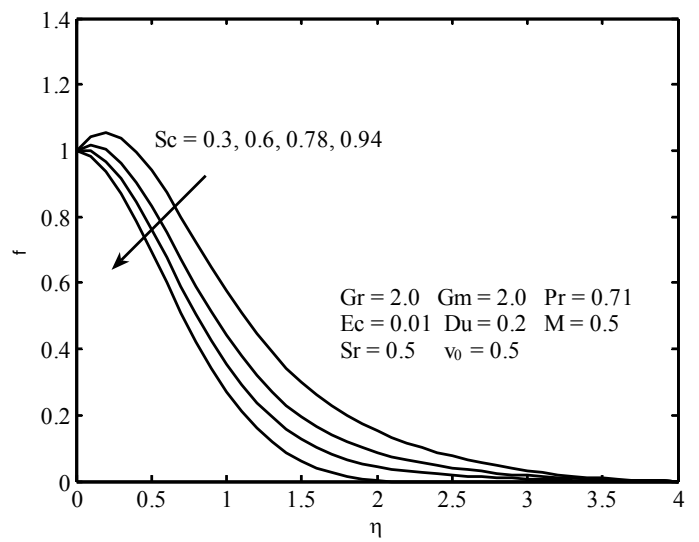

Fig.7(a): Velocity profiles for different values of $S c$

Figs. 7(a) and 7(b) illustrate the velocity and concentration profiles for different values of Schmidt number $S c$. The Schmidt number embodies the ratio of the momentum to the mass diffusivity. The Schmidt number therefore quantifies the relative effectiveness of momentum and mass transport by diffusion in the hydrodynamic (velocity) and concentration (species) boundary layers. It is observed that as the Schmidt number increases the concentration decreases. This causes the concentration buoyancy effects to decrease yielding a reduction in the fluid velocity. The reductions in the velocity and concentration profiles are accompanied by simultaneous reductions in the velocity and concentration boundary layers.

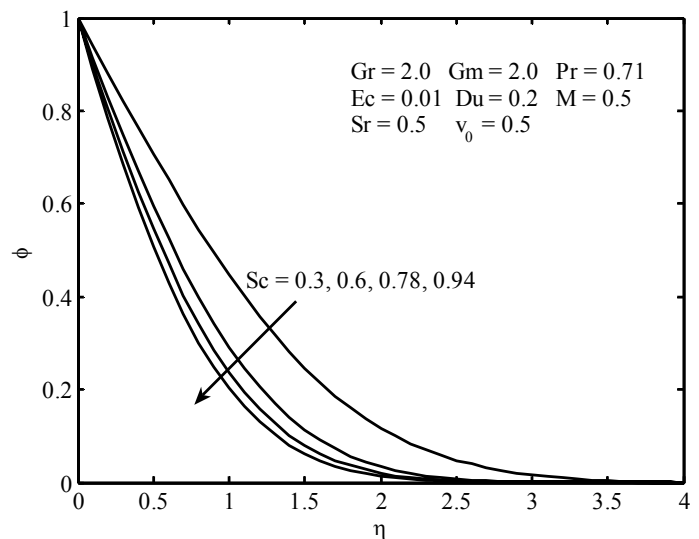

Fig.7(b): Concentration profiles for different values of $S c$

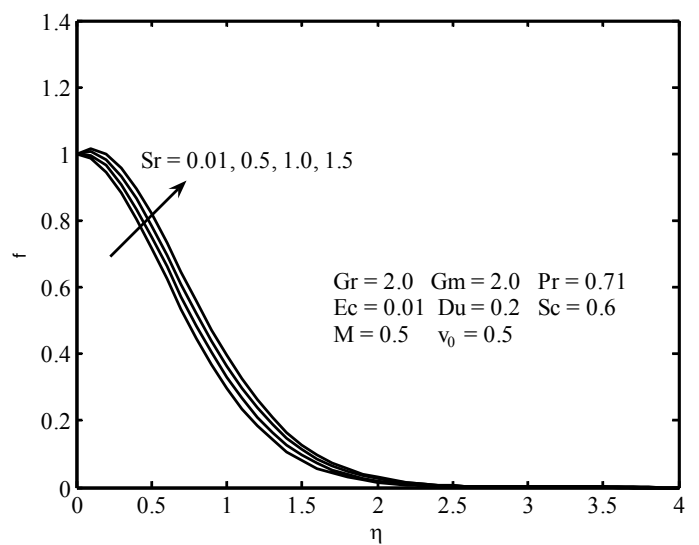

Fig.8(a): Velocity profiles for different values of $\mathrm{Sr}$

The influence of Soret number $S r$, on the dimensionless velocity and concentration are shown in Figs 8(a) and 8(b) respectively. The Soret number $S r$ defines the effect of the temperature gradients inducing significant mass diffusion effects. It is noticed that an increase in the Soret number $S r$ results an increase in the velocity and concentration within the boundary layer.

The effect of suction parameter $v_{0}$ on the velocity, temperature and concentration are shown in Figs. 9(a), 9(b) and 9(c) respectively. It is found that an increase in the suction parameter results a decrease in the velocity, temperature and concentration. 
M. Gnaneswara Reddy, N.Bhaskar Reddy / Journal of Naval Architecture and Marine Engineering 8(2011) 1-12

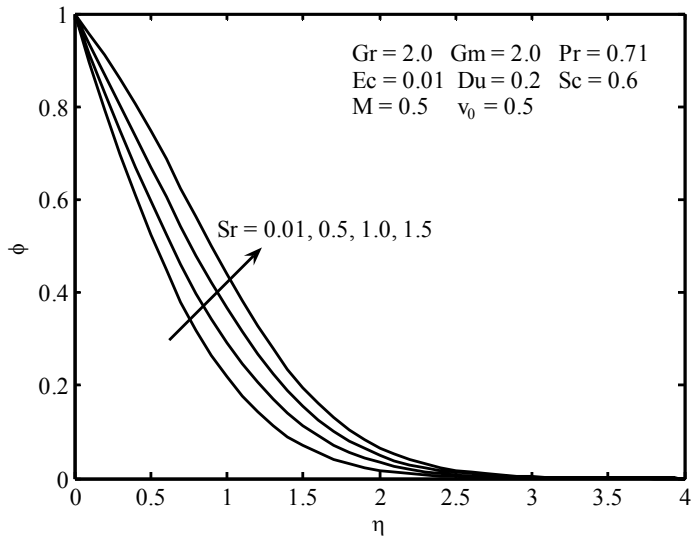

Fig.8(b): Concentration profiles for different values of $\mathrm{Sr}$

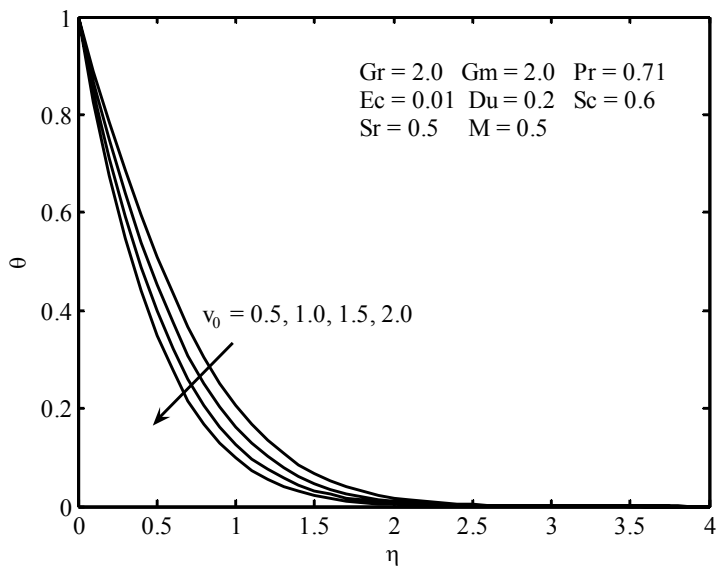

Fig.9(b): Temperature profiles for different values of $v_{0}$

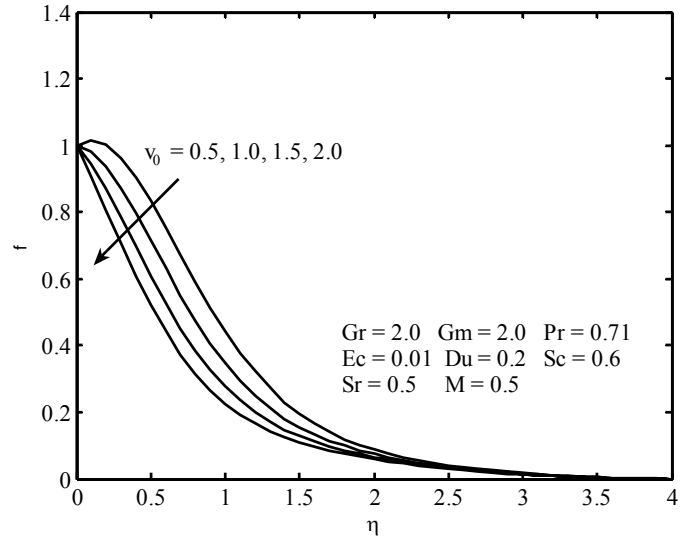

Fig.9(a). Velocity profiles for different values of $v_{0}$

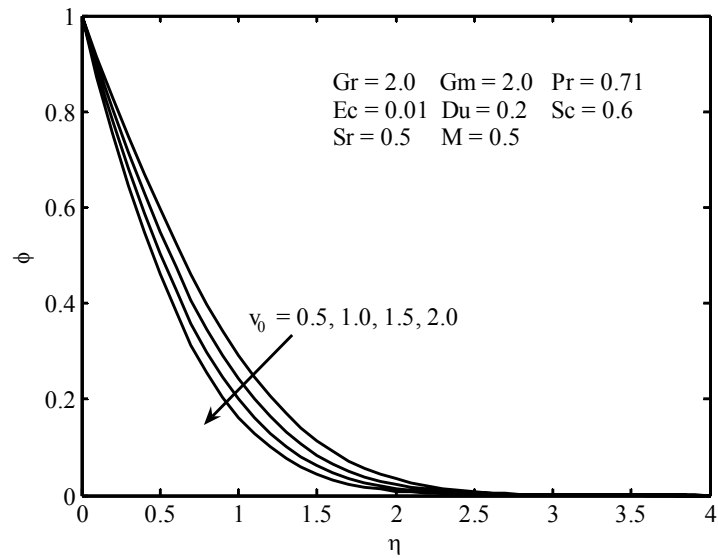

Fig.9(c): Concentration profiles for different values of $v_{0}$

Table 1 Numerical values of the skin-friction coefficient, Nusselt number and Sherwood number for $\operatorname{Pr}=0.71$, $E c=0.01, D u=0.2, S c=0.6, S r=1.0$

\begin{tabular}{|l|l|l|l|l|l|l|}
\hline$G r$ & $G m$ & $M$ & $v_{0}$ & $C_{f}$ & $N u$ & $S h$ \\
\hline 2.0 & 2.0 & 0.5 & 0.5 & 0.13667 & 1.12041 & 0.86906 \\
4.0 & 2.0 & 0.5 & 0.5 & 0.96562 & 1.12856 & 0.86928 \\
2.0 & 4.0 & 0.5 & 0.5 & 1.08165 & 1.12939 & 0.86932 \\
2.0 & 2.0 & 1.0 & 0.5 & 0.08308 & 1.12164 & 0.86908 \\
2.0 & 2.0 & 0.5 & 0.5 & 0.05655 & 1.16602 & 0.89668 \\
\hline
\end{tabular}

Table 2 Numerical values of the skin-friction coefficient, Nusselt number and Sherwood number for $G r=2.0$,

$G m=2.0, M=0.5, v_{0}=0.5$
\begin{tabular}{|l|l|l|l|l|l|l|l|}
\hline $\operatorname{Pr}$ & $E c$ & $D u$ & $S c$ & $S r$ & $C_{f}$ & $N u$ & $S h$ \\
\hline 0.71 & 0.01 & 0.2 & 0.6 & 1.0 & 0.13657 & 1.12041 & 0.86906 \\
1.0 & 0.01 & 0.2 & 0.6 & 1.0 & 0.04929 & 1.38856 & 0.79899 \\
0.71 & 0.02 & 0.2 & 0.6 & 1.0 & 0.13768 & 1.11745 & 0.86782 \\
0.71 & 0.01 & 0.4 & 0.6 & 1.0 & 0.16925 & 1.05172 & 0.88610 \\
0.71 & 0.01 & 0.2 & 0.78 & 1.0 & 0.06718 & 1.10419 & 1.00834 \\
0.71 & 0.01 & 0.2 & 0.6 & 2.0 & 0.23309 & 1.14636 & 0.65036 \\
\hline
\end{tabular}


M. Gnaneswara Reddy, N.Bhaskar Reddy / Journal of Naval Architecture and Marine Engineering 8(2011) 1-12

Tables 1-2 show the effects of the thermal Grashof Number, solutal Grashof number, magnetic field parameter, suction parameter, Prandtl number, Eckert number, Dufour number, Soret number and the Schmidt number on the skin-friction coefficient $C_{f}$, Nusselt number $N u$, and Sherwood number $S h$. From Table 1, it is noticed that as $G r$ or $G m$ increases, there is a rise in the skin-friction coefficient, Nusselt number and the Sherwood number. It is observed that as $M$ increases, there is a fall in the skin-friction coefficient, the Nusselt number and the Sherwood number. It is noticed that as the suction parameter increases, the skin-friction coefficient decreases, while the Nusselt number and the Sherwood number increase. From Table 2, it is found that as $\operatorname{Pr}$ increases there is a decrease in the skin-friction coefficient and Sherwood number, while the Nusselt number increases. It is also observed that an increase in $E c$ or $D u$ leads to an increase in the skin-friction coefficient and Sherwood number while a decrease in the Nusselt number. It is clear that as the Schmidt number increases the skin-friction coefficient and the Nusselt number decrease while the Sherwood number increases. It is also seen that an increase in $\mathrm{Sr}$ leads to an increase in the skin-friction coefficient and Nusselt number while a decrease in the Sherwood number.

\section{Conclusions}

The Soret and Dufour effects of an unsteady free convection flow magnetohydrodynamic and viscous dissipating fluid past an impulsively started vertical plate has been analyzed. With appropriate transformations the boundary layer equations are transformed into nonlinear ordinary differential equations. These equations are solved numerically by a finite element method. From the above mentioned discussion, following conclusions can be drawn:

1. The velocity increases with the increase thermal Grashof number and solutal Grashof number.

2. The velocity decreases with an increase in the magnetic parameter.

3. A positive increase in Eckert number is shown to reduce the velocity and temperatures in the flow.

4. Increasing the Prandtl number substantially decreases the translational velocity and the temperature .

5. An increase in the Dufour number causes a rise in the velocity and temperature throughout the boundary layer.

6. The velocity as well as concentration decreases with an increase in the Schmidt number.

7. An increase in the Soret number results an increase in the velocity and concentration with in the boundary layer.

\section{References}

Callahan G. D. and Marner W. J. (1976): Transient free convection with mass transfer on an isothermal vertical flat plate, Int. J. Heat Mass Transfer, Vol.19, pp.165-174. doi:10.1016/0017-9310(76)90109-5

Soundalgekar V.M. and Wavre P.D. (1977): Unsteady free convection flow past an infinite vertical plate with constant suction and mass transfer, Int. J. Heat Mass Transfer, Vol.20, pp.1363-1373. doi:10.1016/0017-9310(77)90033-3

Soundalgekar V. M. (1979): Effects of mass transfer and free convection currents on the flow past an impulsively started vertical plate, ASME Journal of Applied Mechanics, Vol.46, pp.757-760. doi:10.1115/1.3424649

Shanker B. and Kishan N. (1997): The effects of mass transfer on the MHD flow past an impulsively started infinite vertical plate with variable temperature or constant heat flux, J. Eng. Heat Mass Transfer, Vol.19, pp.273-278.

Elabashbeshy E.M.A. (1997): Heat and mass transfer along a vertical plate with variable temperature and concentration in the presence of magnetic field, Int. J. Eng. Sci., Vol.34, pp.515-522. doi:10.1016/S0020-7225(96)00089-4

Eckert E.R.G. and Drake R. M. (1972): Analysis of Heat and Mass Transfer, McGraw-Hill Book Co., New York.

Finite element analysis of Soret and Dufour effects on unsteady MHD free convection flow ...... 
M. Gnaneswara Reddy, N.Bhaskar Reddy / Journal of Naval Architecture and Marine Engineering 8(2011) 1-12

Dursunkaya Z. and Worek W. M. (1992): Diffusion-thermo and thermal diffusion effects in transient and steady natural convection from a vertical surface, Int. J. Heat Mass Transfer, Vol.35, pp.2060-2065. doi:10.1016/0017-9310(92)90208-A

Kafoussias N.G. and Williams E.M. (1995): Thermal-diffusion and Diffusion-thermo effects on free convective and mass transfer boundary layer flow with temperature dependent viscosity, Int. J. Eng. Science, Vol.33, pp.1369-1376. doi:10.1016/0020-7225(94)00132-4

Anghel M., Takhar H.S. and Pop I. (2000): Dufour and Soret effects on free convection boundary layer over a vertical surface embedded in a porous medium, J. Heat and Mass Transfer. Vol. 43, pp.1265-1274.

Postelnicu A. (2004): Influence of a magnetic field on heat and mass transfer by natural convection from vertical surfaces in porous media considering Soret and Dufour effects, Int. J. Heat Mass Transfer, Vol.47, pp.1467-1472. doi:10.1016/j.ijheatmasstransfer.2003.09.017

Gebhart B. (1962): Effects of viscous dissipation in natural convection, J. Fluid Mech., Vol.14, pp.225-232. doi:10.1017/S0022112062001196

Gebhart B. and Mollendorf J. (1969): Viscous dissipation in external natural convection flows, J. Fluid Mech., Vol.38, pp.97-107. doi:10.1017/S0022112069000061

Soundalgekar V.M. (1972): Viscous dissipation effects on unsteady free convective flow past an infinite vertical porous plate with constant suction, Int. J. Heat Mass Transfer, Vol.15, pp.1253-1261. doi:10.1016/00179310(72)90189-5

Hasimoto H. (1956): Boundary layer growth on a flat plate with suction or injection, J. Phys. Soc. Japan, Vol.12, pp.68-72. doi:10.1143/JPSJ.12.68

Sattar M.A. and Hossain M.M. (1992): Unsteady hydromagnetic free convection flow with Hall current and mass transfer along an accelerated porous plate with time dependent temperature and concentration, Can. J. Phys., Vol.70, pp.369-374. doi:10.1139/p92-061

Sattar M. A., Rahman M. and Alam M. (2000): Free convection flow and heat transfer through a porous vertical flat plate immersed in a porous medium with variable suction, J. Energy Heat and Mass Transfer, Vol.22, pp.1721

Schlichting H. (1968): Boundary Layer Theory, McGraw-Hill, New York. Reddy J.N. (1985): An Introduction to the Finite Element Method, McGraw-Hill, New York. Bathe K. J. (1996): Finite Element Procedures, Prentice-Hall, New Jersey. 